\title{
Intensity of Long-Term Treatment with Warfarin Is Influenced by Seasonal Variations
}

\author{
Barbara Salobir Mišo Šabovič Polona Peternel \\ Department of Vascular Diseases, University Medical Centre, Ljubljana, Slovenia
}

\section{Key Words}

Warfarin · Prothrombin time $\cdot$ International normalised ratio $\cdot$ Seasonal variations

\begin{abstract}
In a prospective study, which lasted 1 year and was performed on a large cohort of 800 patients treated at an outpatient anticoagulant clinic, we investigated possible seasonal variations in the intensity of the effect of warfarin treatment. For every season - winter, spring, summer and autumn - the mean prothrombin time reported as an international normalised ratio (INR) and the percentages of INR below 2.0 and above 4.0 were calculated. Significant seasonal variations in mean INR measurements were found, with the lowest values in summer and the highest values in autumn ( $F=14.2, p<0.0001)$. In addition, a trend toward a higher percentage of INR below 2.0 in summer and above 4.0 in autumn was observed. No significant differences were found between older $(>65$ years) and younger ( $<65$ years) patients, although there was a trend toward more pronounced variations in younger patients. Consideration of seasonal variations might result in more accurate and safe guidance of warfarin treatment.
\end{abstract}

Copyright @ 2002 S. Karger AG, Basel

\section{Introduction}

Warfarin is a very potent and widely used drug for the prevention of venous thromboembolism and systemic embolisms in atrial fibrillation, prosthetic heart valves, congestive cardiomyopathy and certain types of valvular heart disease; it is also effective in the prevention of thrombotic events in patients with ischaemic heart disease and in peripheral arterial obstructive disease [1]. Its therapeutic effectiveness is monitored by prothrombin time (PT) and reported as international normalised ratio (INR) [1]. The effectiveness and safety of treatment with warfarin are critically dependent on maintaining the INR in the therapeutic range [2]. Thus, knowledge about factors which could influence the intensity of the effect of warfarin is highly desirable.

Besides the dose of warfarin, many factors, such as individual sensitivity, change in dietary habits, concurrent diseases and usage of drugs, which interact with the metabolism of warfarin may influence the stability of treatment and the time in which patients' INRs are in the therapeutic range [1]. Since all these factors may vary cyclically over the seasons, they may periodically directly or indirectly influence the patients' sensitivity and thereby produce seasonal variations in the intensity of the effect of warfarin. In a preliminary, non-systematic pilot

\begin{tabular}{ll}
\hline KARGER & ( ) 2002 S. Karger AG, Basel \\
Fax +4161306 1234-8832/02/0324-0151\$18.50/0 \\
$\begin{array}{l}\text { E-Mail karger@karger.ch } \\
\text { www.karger.com }\end{array}$ & $\begin{array}{l}\text { Accessible online at: } \\
\text { www.karger.com/pht }\end{array}$
\end{tabular}

Mišo Šabovič, MD, PhD

Department of Vascular Diseases

University Medical Centre Ljubljana

Riharjeva 24, 1000 Ljubljana (Slovenia)

Tel. +386 1283 3500, Fax +3861283 3155, E-Mail miso.sabovic@trnovo.kclj.si 
Table 1. Age (means with ranges in parentheses), number and percentage of females, indications for warfarin treatment (numbers and percentage) and daily dose of warfarin (means with standard deviation) in older ( $>65$ years) and younger ( $<65$ years) group

\begin{tabular}{lccc}
\hline & $\begin{array}{l}\text { Older group } \\
(\mathrm{n}=347)\end{array}$ & $\begin{array}{l}\text { Younger group } \\
(\mathrm{n}=453)\end{array}$ & $\mathrm{p}$ value \\
\hline Age, years & $73(66-90)$ & $55(16-65)$ & \\
Females & $190(55 \%)$ & $163(36 \%)$ & $<0.05$ \\
Indications for warfarin & $32(9.2 \%)$ & $100(22.1 \%)$ & $<0.001$ \\
Prosthetic heart valves & $230(66.3 \%)$ & $244(53.8 \%)$ & $\mathrm{NS}$ \\
Atrial fibrillation & $77(22.2 \%)$ & $101(22.3)$ & $\mathrm{NS}$ \\
Venous thromboembolisms & $8(2.3 \%)$ & $8(1.8 \%)$ & $\mathrm{NS}$ \\
Peripheral arterial occlusive disease & $2.0 \pm 2.5$ & $2.5 \pm 3.2$ & $<0.05$ \\
Daily dose of warfarin (mg) & & & \\
\hline
\end{tabular}

study, we observed seasonal variations, which seemed to be more pronounced in younger patients. Thus, the aim of the present prospective study on a large sample of patients on chronic treatment with warfarin was first to investigate whether there are indeed seasonal variations in the intensity of the effect of treatment and second whether seasonal variations differ between older and younger patients.

\section{Patients and Methods}

Eight hundred patients (353 (44\%) females, 447 (56\%) males) of mean age 64 (18-to 90 ) years on chronic stable treatment with warfarin (duration of treatment at the beginning of the study 1-313 months, mean 52 months) were followed prospectively at the outpatient anticoagulant clinic of our university hospital for 1 year. The cohort of patients was unchanged during the study period. Three skilled physicians who had worked in the outpatient anticoagulant clinic for many years routinely prescribed the dose of warfarin according to the INR value. PT was measured by the Thrombotest (Nycomed, Norway, ISI $=1.05)$. The target INR value was $2.5-3.5$ for mechanical heart valves and 2-3 for all other indications. Patients were divided into two groups: older than 65 years and younger than 65 years.

The year was divided into four seasons: winter - December, January, February; spring - March, April, May; summer - June, July, August, and autumn - September, October, November. For every season, the number of PT measurements was counted. The mean values of INR, the percentages of INR below 2.0 and above 4.0 were calculated for every season firstly for the whole group and secondly separately for the older and younger groups of patients. The time in the therapeutic range (TTR) was determined as the proportion of INR measurements within the therapeutic range in the observed period of time; the number of INRs within the range was divided by the number of PT tests in the same period of time, a method previously described in many studies [3]. We compared the number of PT measurements across the four seasons using a non-parametric observed vs. expected frequency $\chi^{2}$ test. The null hypothesis was that the means of INR were not different across the four seasons using a non-parametric one-way ANOVA test. The null hypothesis that the percentage of PT measurements with INR below 2.0 or over 4.0 was the same all over the four seasons was tested using the $\chi^{2}$ test to compare the observed percentage with that expected on the basis of an even distribution. Differences in means of INR for every season between the older and younger groups were tested by the $t$ test for independent samples and differences in the percentages of INR below 2.0 or over 4.0 , by the $\chi^{2}$ test. Values of $p<0.05$ were assumed to be statistically significant. Statistical analyses were performed by the Statistica for Windows computer program (Stat Soft, Inc., Tulsa, Okla., USA).

\section{Results}

Mean age, indications for warfarin treatment and mean daily dose of warfarin for both groups are shown in table 1 . The percentage of females was significantly greater in the older group. Significantly more patients in the younger group had mechanical heart valves and the mean daily dose of warfarin was significantly greater in the younger than in the older patients.

The mean number of PT measurements per season was 927 (winter 712, spring 1,100, summer 1,006, autumn 890). The difference in the number of PT measurements between seasons was significant $\left(\chi^{2}=90, p<0.000\right)$. The mean TTR was $67 \%$ and did not differ between age groups nor within seasons, although a trend toward higher TTRs in the younger group as compared to the older group was observed in winter (fig. 1).

We found statistically significant seasonal variations between mean INR measurements, with the lowest values in summer and the highest values in autumn in all patients $(\mathrm{F}=14.2, \mathrm{p}<0.0001)$, in the older group $(\mathrm{F}=4.8$, 


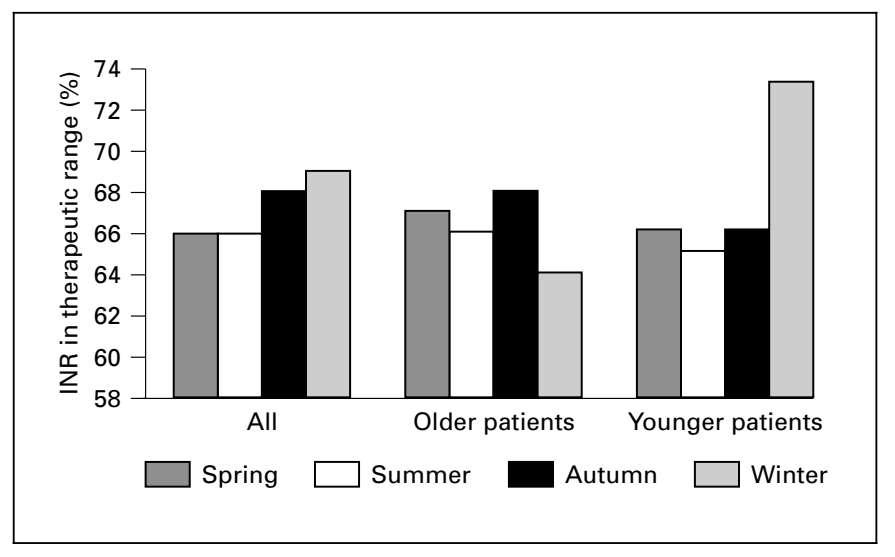

Fig. 1. TTR over seasons expressed as percent of INR in the therapeutic range in all, older ( $>65$ years) and younger ( $<65$ years) group of patients.

Table 2. Mean INR with standard deviation in all, older ( $>65$ years) and younger $(<65$ years) group of patients for each season of the year

\begin{tabular}{llll}
\hline & $\begin{array}{l}\text { All patients } \\
(\mathrm{n}=800)\end{array}$ & $\begin{array}{l}\text { Older group } \\
(\mathrm{n}=347)\end{array}$ & $\begin{array}{l}\text { Younger group } \\
(\mathrm{n}=453)\end{array}$ \\
\hline Spring & $2.9 \pm 1.1$ & $2.9 \pm 1.4$ & $2.9 \pm 1.2$ \\
Summer & $2.7 \pm 1.2$ & $2.6 \pm 1.2$ & $2.7 \pm 1.1$ \\
Autumn & $3.1 \pm 1.3$ & $2.9 \pm 1.1$ & $3.2 \pm 1.4$ \\
Winter & $2.8 \pm 1.0$ & $2.8 \pm 1.1$ & $2.9 \pm 1.2$ \\
\hline F & 14.2 & 4.8 & 12.2 \\
\hline p value & $<0.000$ & $<0.005$ & $<0.000$ \\
\hline
\end{tabular}

$\mathrm{p}<0.005)$ and in the younger group $(\mathrm{F}=12.2, \mathrm{p}<0.0000)$ (table 2, fig. 2a). In addition, a trend toward the highest percentage of INRs below 2.0 in summer and above 4.0 in autumn was seen in all patients (fig. $2 b, c)$. We did not find any statistically significant differences in the seasonal trends between the older and younger groups of patients; however, the trends were more pronounced in the younger group of patients in which the difference between summer and winter in the percentage of INR below 2.0 reached statistical significance $\left(\chi^{2}=4.78, \mathrm{p}<0.05\right)$.

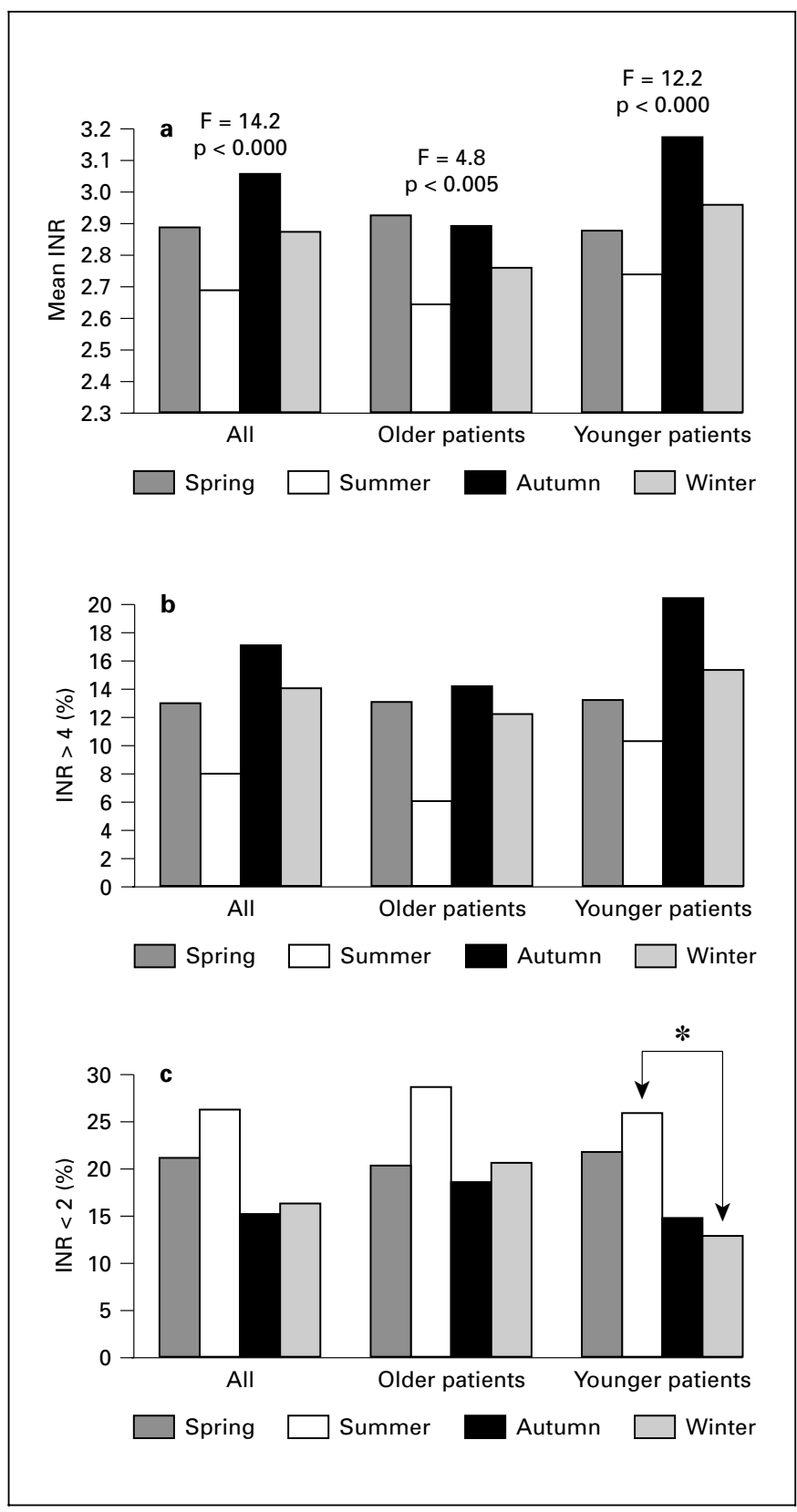

Fig. 2. Seasonal variation of INR means (a), \% INR $>4$ (b) and $\%$ INR $<2$ (c) in all, older ( $>65$ years) and younger ( $<65$ years) group of patients. ${ }^{*} \mathrm{p}<0.05$.

\section{Discussion}

The results of our prospective study, performed on a large cohort of patients treated with warfarin, showed seasonal variations in the intensity of the effect of treatment. The lowest mean INR values were found in summer and the highest mean INR values in autumn. Thus, autumn

Pathophysiol Haemost Thromb 2002;32:151-154 
was the season with the highest rate of exceedingly intense effects of treatment. Seasonal variations in the intensity of the effect of warfarin treatment might be an important, as yet unknown risk factor for haemorrhagic and thrombotic complications in patients on long-term warfarin treatment.

The mechanisms of seasonal variations in the intensity of the effects of warfarin treatment are as yet unknown. Several plausible direct or indirect factors, such as individual seasonal changes in sensitivity to warfarin, seasonal changes in consumption of vitamin-K-rich vegetables during summer, a higher consumption of alcohol during autumn, a higher rate of febrile states due to infections during autumn, winter and spring compared to summer and a lower compliance with warfarin treatment during summer due to holidays might all be implicated in the mechanisms of seasonal variations in the intensity of the effects of long-term warfarin treatment [4-7]. Our findings in a large cohort of patients, prospectively followed for 1 year, are in agreement with a previous, retrospective study on a smaller number of patients (382 patients who had been on long-term oral anticoagulant treatment for 5 years due to mechanical heart valves, cardiovascular disease or venous thromboembolism), in which Mannotti et al. [8] also found similar seasonal variations in means of INR with the lowest values in spring and summer and the highest in autumn and winter. In our study, we did not find any significant differences in seasonal variations in the intensity of the effect of warfarin treatment between older ( $>65$ years) and younger $(<65$ years) patients; however, trends toward the highest percentage of INR below 2.0 in summer and above 4.0 in autumn were more pronounced in younger than in older patients. It might be speculated that seasonal variations in the intensity of the effect of treatment might be a more important risk factor for complications of warfarin treatment in younger than in older patients; however, further studies are needed to test this hypothesis.

Clinical advice arising from our results would be to consider the role of seasonal variations in the intensity of the effect of warfarin treatment and to pay additional attention to the intensity of this effect in autumn, the season with the highest risk of excess of over-intensity. This could be approached by more frequent measurements of INR. The results of some clinical trials suggest that more frequent testing can improve TTR [9].

In conclusion, our study showed significant seasonal variations in the intensity of the effect of warfarin treatment in patients on long-term warfarin treatment, with the lowest mean INR values in summer and highest mean INR values in autumn. We did not find any significant differences in seasonal variations between younger and older groups of patients, although there is a trend toward more pronounced variations in younger patients. Our findings seem to have clinical importance, since consideration of seasonal variations in the intensity of the effect of warfarin might result in more accurate and safe guidance of warfarin treatment.

\section{References}

1 Hirsh J, Dalen JE, Anderson DR, Poller L, Bussey H, Ansell J, Deykin D: Oral anticoagulants. Mechanism of action, clinical effectiveness and optimal therapeutic range. Chest 2001;119:8S$21 \mathrm{~S}$.

2 Levine MN, Raskob G, Landefeld S, Kearon C: Hemorrhagic complications of anticoagulant treatment. Chest 2001;119:108S-121S

3 Ansell J, Hirsh J, Dalen J, Bussey H, Anderson D, Poller L, Jacobson A, Deykin D, Matchar D: Managing oral anticoagulant therapy. Chest 2001;119:22S-38S.
4 Lubetsky A, Dekel-Stern E, Chetrit A, Lubin F, Halkin H: Vitamin $\mathrm{K}$ intake and sensitivity to warfarin in patients consuming regular diets. Thromb Haemost 1999;81:396-399.

5 Hylek EM, Heiman H, Skates SJ, Sheehan MA, Singer DE: Acetaminophen and other risk factors for excessive warfarin anticoagulation. JAMA 1998;297:657-662.

6 Fihn SD, McDonnel M, Martin D, Henikoff J, Vermes D, Kent D, White RH: Risk factors for complications of chronic anticoagulation: A multi-centre study. Warfarin Optimized Outpatient Follow-up Study Group. Ann Intern Med 1993;118:511-520.
7 Karlson B, Leijd B, Hellstrom K: On the influence of vitamin K-rich vegetables and wine on the effectiveness of warfarin treatment. Acta Med Scand 1986;220:347-350.

8 Mannotti C, Quintavalla R, Pattacini C, Pini $\mathrm{M}$ : Seasonal variation of oral anticoagulant effect. Thromb Haemost 1994; 71:802-803.

9 Horstkotte D, Piper C, Weimer M: Optimal frequency of patient monitoring and intensity of oral anticoagulation therapy in valvular heart disease. J Thromb Thrombolysis 1998;5: S19-S24. 